PÍA MONTEALEGRE

Profesora asistente, Instituto de Historia y Patrimonio, FAU, Universidad de Chile, Santiago, Chile rchitecture has a long relationship with solidity, gravity, and mass. To Alberti, it was the rational form of a displacement of weights and chaining of bodies. Much of the architectural virtue has been to play with the possibilities of both operations. The threshold geometry of the gravitational force dictated the shape of the pillars at Johnson Wax or the paraboloids at the Sagrada Familia.

That material and rational aspect of architecture is located in the sphere of control and certainties. Maybe that is why Koolhaas' definition of contemporary architecture as a risky mix of omnipotence and impotence causes uneasiness. It seems that the architects are happier when the scale leans in favor of the first thing. The dominance renunciation and the embrace of postmodern complexity have been more of a challenge than a goal.

Thanks to their program's simplicity, pavilions can carry other theoretical tasks and appeal to those borders. The premise in the pavilion is inserting itself in that uncomfortable point of the dissolution of certainties. In fact, it doesn't have a defined shape beforehand. It is a casual, circumstantial, and mutant result of external forces. In the end, air, even when controlled by turbines, is only a means, not a material. Strictly speaking, the pavilion is made up of fans and a piece of fabric, of impulses and a sensor. Thus, we are in front of an architecture that renounces to support, becoming stimulus and reflection instead.

In regular times and circumstances, perhaps the pavilion would have spoken only about that material expression in a mutant way. But the context's narrative ended up completing it with greater dramatic intensity. The uprising of October 2019, at a close distance from the university premises, hindered and trivialized any form of celebration. Then came the pandemic, suppressing collective life. Hence, the pavillion ended up celebrating the anniversary of the introduction of architecture in Chile's higher education in an empty college courtyard. Designed, assembled, and disassembled in a scenario of complete uncertainty, the fabric waved in a few-minutes clip, streamed on social media. It probably rocked in Santiago's breeze for far more hours, but no one could see it.

Despite this discreet and solitary existence, it was an inhabited place, albeit in a somewhat sui generis way. It was the symbolic venue for a series of 


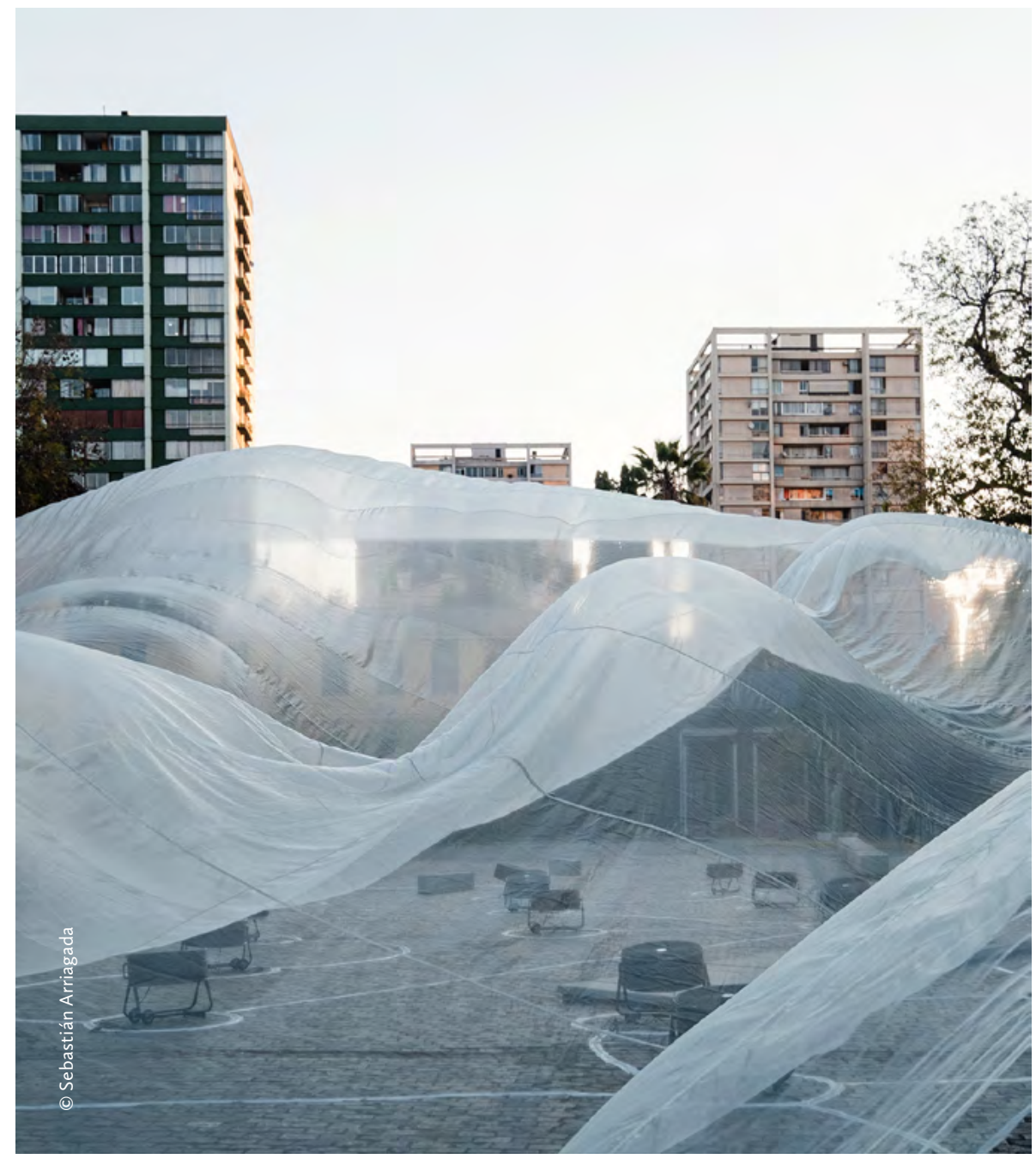

ceremonies and conferences that, although broadcasted from different points in the city, virtually brought together a community in the cobblestone courtyard. It was a landmark, a mark in space (pavilions are also flags, aren't they?), a name associated with an image. It was a meeting place located in our memory, like so many other spaces that we have learned to inhabit during confinement. If current times demand disciplines to respond in new ways, the circumstances transformed the Wind Pavilion into a hopeful metaphor for future architecture: more receptive than decisive; of a more caring than material existences. ARQ

\section{Pía Montealegre}

$<$ mmontealegre@uchile.cl>

Architect, Pontificia Universidad Católica de Chile, 2003. Master in Urban Development, Pontificia Universidad Católica de Chile, 2010. $\mathrm{PhD}$ in Architecture and Urban Studies, Pontificia Universidad Católica de Chile, 2017. Her research areas are urban history, public space and the culture of the city. She is a Montealegre Beach Architects partner Assistant professor at the Institute of History and Heritage, FAU, 